\title{
Mudanças na Política Nacional de Atenção Básica: entre retrocessos e desafios
}

\author{
Changes in the National Policy of Primary Health Care: between \\ setbacks and challenges
}

Eduardo Alves Melo', Maria Helena Magalhães de Mendonça ${ }^{\mathbf{2}}$, Jarbas Ribeiro de Oliveira ${ }^{\mathbf{3}}$, Gabriella Carrilho Lins de Andrade ${ }^{4}$

DOI: 10.1590/0103-110420185103

\footnotetext{
1 Fundação Oswaldo Cruz (Fiocruz), Escola Nacional de Saúde Pública Sergio Arouca (Ensp) - Rio de Janeiro (RJ), Brasil. Orcid: https://orcid. org/0000-0001-58814849 eduardo.melo@ensp. fiocruz.br

2 Fundação Oswaldo Cruz (Fiocruz), Escola Nacional de Saúde Pública Sérgio Arouca (Ensp) - Rio de Janeiro (RJ), Brasil. Orcid: https://orcid. org/0000-0002-39179103

mhelenam@ensp.fiocruz.br

3 Fundação Oswaldo Cruz (Fiocruz), Escola Nacional de Saúde Pública Sérgio Arouca (Ensp), Programa de Pós-Graduação em Saúde Pública - Rio de Janeiro (RJ), Brasil. Universidade Federal de Alagoas (Ufal) - Arapiraca (AL), Brasil. Orcid: https://orcid org/0000-0001-85192432

jarbasribeiroo@gmail.com

${ }^{4}$ Fundação Oswaldo Cruz (Fiocruz), Escola Nacional de Saúde Pública Sérgio Arouca (Ensp), Programa de Pós-Graduação em Saúde Pública - Rio de Janeiro (RJ), Brasil. Orcid: https://orcid. org/0000-0001-87363039

andrade.gabriella@gmail. com
}

RESUMO O artigo reflete sobre a Política Nacional de Atenção Básica (PNAB) em suas diversas versões. Seus objetivos foram discutir os contextos da revisão da PNAB em sua edição de 2017, comparar com a versão de 2011 e identificar elementos de continuidade, descontinuidade e possíveis agregações. Partiu das portarias que definem a PNAB, seguido de leitura sistemática e eleição de dimensões de análise e de comportamento quanto à coerência e a contradições. Destacou os fóruns de debate e os principais atores envolvidos na revisão. Destacou, como resultados, a preservação da base conceitual da Atenção Básica (AB). Alterações significativas na dimensão organizativa e funcional indicam flexibilização da modalidade de organização - Estratégia Saúde da Família (ESF) e AB tradicional. Adicionalmente, mudanças na composição da equipe, no quantitativo de Agentes Comunitários de Saúde (ACS) e nas suas atribuições singulares. Na gestão, a novidade é a gerência da Unidade Básica de Saúde. No financiamento, preservou as responsabilidades dos três entes federados, com baixa perspectiva de ampliação de recursos financeiros. Chamou atenção o protagonismo dos gestores formais e a desconsideração dos posicionamentos do controle social na tomada de decisão. Considera que há dispositivos da PNAB que induzem, impedem ou condicionam mudanças, e conclui que os propósitos centrais dessa agenda são a diminuição dos ACS e mudança de seu perfil, bem como a priorização da chamada $\mathrm{AB}$ tradicional em detrimento da ESF. Ademais, tal mudança, em conjuntura de crise política e econômica do País, com o Ministério da Saúde assumindo uma agenda neoliberal, faz-se inoportuna e oferece condições de desmonte da ESF, além de aprofundar a cisão entre atores da política de saúde.

PALAVRAS-CHAVe Atenção Primária à Saúde. Estratégia Saúde da Família. Política de saúde. Sistema Único de Saúde.

ABSTRACT The article reflects on the National Policy of Primary Health Care (PNAB) in its
various versions. Its objectives are to discuss the contexts of the PNAB review on your 2017
edition, compare with the 2011 version and identify elements of continuity, discontinuity, and
possible aggregations. It starts from the ordinances that define the PNAB, followed by systematic
reading and election of analysis and behavioral dimensions as for coherence and contradictions,
highlighting the discussion forums and the main actors involved in the review. It highlighted
as results the preservation of the conceptual approach of Primary Care (AB). Changes that are 
significant in the organizational and functional dimension indicate easing in the organization mode - Family Health Strategy (ESF) and AB. Additionally, changes in the composition of the team, as for the number of Community Health Workers (ACS) and its unique assignments. In management, the novelty is the management of the Health Center. In financing, it preserved the responsibilities of the three federated entities, with a low perspective of expansion of financial resources. Attention was drawn to the role of formal managers and to disregarding the positions of social control in decision-making. It is considered that there are PNAB devices that induce, prevent or condition changes, and concludes that the central purposes of this agenda are to reduce the ACS and to change its profile as well as the prioritization of the so-called traditional $A B$ to the detriment of the ESF. Furthermore, such a change, in conjuncture of political and economic crisis of the country, with the Ministry of Health assuming a neoliberal agenda, makes it inopportune and offers conditions of dismantling the ESF, besides deepening the division among the actors of health policy.

KEYWORDS Primary Health Care. Family Health Strategy. Health policy. Unified Health System.

\section{Introdução}

\section{Breve contextualização histórica}

A Atenção Primária à Saúde (APS) tem sido pensada, internacionalmente, desde o início do século XX, com destaque para o seu desenho no relatório Dawson de 1922, materializando-a na figura do médico geral, no contexto de uma rede territorial de serviços nucleada a partir dos centros primários, com autoridade sanitária regional. Esta formulação serviu de base para a construção do Serviço Nacional de Saúde inglês, importante referência de sistema público e universal de saúde'.

A conferência internacional de Alma Ata, no final dos anos 1970, influenciada pelo cenário político econômico dos países e pelos custos do setor saúde ${ }^{2}$, incorporou elementos dessas experiências, propondo os cuidados primários em saúde como elemento central para mudanças no setor saúde e na vida social ${ }^{3}$.

Uma importante formulação concebeu a APS a partir da ideia de atributos, destacando-se: o primeiro contato, a abordagem integral, a continuidade e longitudinalidade, a coordenação, a abordagem familiar e comunitária ${ }^{4}$, referindo-se ao grau de busca da APS pelas pessoas, ao grau de vinculação e relacionamento entre APS e pessoas sob seus cuidados, à capacidade resolutiva e ao poder para coordenar casos e fluxos assistenciais.

Diferentes países do mundo têm APS no seu sistema de saúde. O ideário de Alma Ata é frequentemente destacado como marco fundamental para a APS, com traduções e incorporações heterogêneas nos países, ora como APS seletiva, ora como APS ampliada, com forte influência de organismos internacionais ${ }^{5}$.

\section{APS no Brasil}

As primeiras experiências de APS no Brasil datam da primeira metade do século XX. Desde 1990, com base na nova ordem social definida na Constituição de 1988, que assumiu a saúde como direito de cidadania e criou o Sistema Único de Saúde (SUS), busca-se implementar os princípios e diretrizes 
formulados pelo movimento da reforma sanitária. Nesse período, o esforço de construção de um novo modelo assistencial se materializou, na APS, com a implantação do Programa de Agentes Comunitários de Saúde (Pacs), do Programa de Saúde da Família (PSF), em um contexto e conjuntura política e econômica desfavoráveis a políticas universalistas. A partir de 1996, o PSF passou a ser apresentado como estratégia de mudança do modelo assistencial, superando o conceito de programa vinculado a uma noção de verticalidade e transitoriedade, sendo a Estratégia Saúde da Família (ESF) uma certa fusão do Pacs com o PSF6. Inicialmente com caráter seletivo ${ }^{7}$, as Equipes de Saúde da Família (EqSF) tiveram crescimento marcante em cidades pequenas e em regiões mais pobres, expandindo-se com maior força para os grandes centros nos anos $2000^{8}$.

A introdução dos Pisos de Atenção Básica (PAB) fixo e variável na década de 1990, operados por meio de repasse financeiro fundo a fundo, facilitou a implantação da ESF e superou a lógica de financiamento por convênio e produção (procedimentos), tendo caráter relativamente redistributivo e tipo de repasse mais global por meio do PAB Fixo (per capita) e do PAB-Variável (por adesão a componentes da ESF).

Com evolução progressiva ao longo dos anos, em 2017, havia 42.467 EqSF implantadas no Brasil, cobrindo uma população estimada de 131.349 .487 pessoas ou $63.73 \%$. Há evidências de impactos da APS no Brasil, com destaque para a mortalidade infantil10.

A APS no Brasil conta com a particularidade de ter em suas equipes o Agente Comunitário de Saúde (ACS) como membro de uma equipe multiprofissional. Diversos estudos abordam a singularidade do ACS na experiência brasileira e a importância do seu trabalho, sobretudo em áreas mais pobres ${ }^{6,11}$.

No Brasil, além de formulações internacionais, também têm sido agregados outras perspectivas, conceitos e diretrizes - a APS é também chamada de Atenção Básica $(\mathrm{AB})$, como significante de resistência à APS seletiva. Neste artigo, tais termos serão utilizados como equivalentes. Nas formulações do Pacs e do PSF, tanto a vigilância em saúde como as práticas de promoção à saúde (incluindo a intersetorialidade) e prevenção de doenças tiveram centralidade, com pouca relevância dada às práticas clínicas, subsumidas por ações programáticas em saúde com destacada normatividade ${ }^{2}$. Destacam-se no Brasil, também, as noções de acolhimento, vínculo e adscrição de clientela, territorialização e responsabilidade sanitária, trabalho em equipe multiprofissional, as ações individuais e coletivas e a retaguarda do apoio matricial. Salientam-se as características de porta de entrada preferencial da APS, centro de comunicação e base de ordenamento nas Redes de Atenção à Saúde (RAS) ${ }^{\mathbf{1 2}}$.

\section{Edições da PNAB e a revisão atual}

A primeira edição de uma Política Nacional de Atenção Básica (PNAB) oficial data de 2006, com a segunda edição em 2011 e a terceira em 2017. Em 2006, no contexto do Pacto pela Saúde, foi publicada a primeira edição da PNAB. Esta ampliou o escopo e a concepção da $\mathrm{AB}$ ao incorporar os atributos da atenção primária à saúde abrangente, reconheceu a Saúde da Família como modelo substitutivo e de reorganização da $\mathrm{AB}$. Além disso, revisou as funções das Unidades Básicas de Saúde (UBS) e reconheceu a existência de diferentes modalidades segundo o modelo de organização predominante - UBS com ou sem ESF ${ }^{\mathbf{1 3}, 7}$.

Os anos 2000 estiveram fortemente marcados pela expansão da ESF nos grandes centros urbanos, pela incorporação e ampliação das Equipes de Saúde Bucal (ESB) e pela criação dos Núcleos de Apoio à Saúde da Família (Nasf). A despeito disso, importantes nós críticos persistiram, tais como a infraestrutura inadequada, o subfinanciamento, o modelo assistencial e a dificuldade de atração de profissionais médicos. 
Em 2011, iniciou-se um movimento de mudança da PNAB, em boa parte baseado no enfrentamento desses nós críticos. De fato, podemos reconhecer na PNAB de 2011, no Requalifica UBS (reformas, ampliações, construções e informatização), no Programa de Melhoria do Acesso e da Qualidade (PMAQ) e no Programa Mais Médicos (PMM) expressões desse esforço ${ }^{14}$. Nesse período também foi criado o e-SUS $\mathrm{AB}$, incluindo a oferta de prontuário eletrônico gratuito para os municípios, e foram alteradas normativas visando à sua ampliação e ao aprimoramento. Destaca-se ainda a criação de diferentes modalidades de equipes (consultórios na rua, ribeirinhas e fluviais, por exemplo). Suportando tais iniciativas, observou-se incremento no orçamento federal da $\mathrm{AB}$, notadamente no $\mathrm{PAB}$ Variável e em recursos de investimento ${ }^{15}$. O PMM (no seu componente provimento), por exemplo, possibilitou maior permanência dos médicos nas EqSF em áreas de maior vulnerabilização social, bem como o crescimento da cobertura da ESF, em um processo de disputa com a categoria médica e que provocou debates na sociedade, para além do SUS e da saúde coletiva ${ }^{16}$. Em 2013, havia 34.724 EqSF implantadas no Brasil, passando a 40.162 EqSF em 2015, com esta velocidade de crescimento do número de equipes provavelmente se devendo ao PMM. Essas iniciativas, no entanto, não foram suficientes para o enfrentamento do subfinanciamento, da precarização das relações de trabalho, da formação profissional, da integração da $\mathrm{AB}$ com os demais componentes das redes de atenção, entre outros, em parte pelo tempo de sua implantação, em parte por seus limites ${ }^{\mathbf{1 6}}$.

É sabido que houve aumento da carga de responsabilidade dos municípios no financiamento do SUS ao longo dos anos e, no caso da $\mathrm{AB}$, a baixa participação do ente estadual. A isso se somam reivindicações dos gestores municipais por mais autonomia, apoio financeiro e provimento de médicos, em parte, contempladas, no âmbito da $\mathrm{AB}$, com as mudanças na PNAB a partir de 2011. Ainda assim, há evidências que apontam que a maior parte da responsabilidade pelo custeio das EqSF tem se concentrado nos municípios ${ }^{17}$.

Os anos 2014 e 2015, por sua vez, foram marcados pelo início de grave crise política e econômica no País, com impacto sobre o SUS. No plano da AB, destaca-se também a aprovação, em 2014, da lei federal com definição de piso salarial e obrigatoriedade de contratação apenas por vínculos diretos, para os ACS e Agentes de Combate às Endemias (ACE), recaindo mais fortemente sobre os municípios, em virtude da responsabilidade pela contratação de profissionais ${ }^{18}$. Em 2016, ganha destaque na agenda nacional a revisão da PNAB, precedida por uma portaria que facultava a presença de ACS nas equipes e incorporação de mais técnicos de enfermagem, em pouco tempo revogada diante das repercussões políticas. Houve também mudança nas regras do financiamento federal do SUS em 2017, encaminhando-se para o fim dos seis blocos de financiamento do SUS (um deles da AB) e para a adoção de dois grandes blocos, de custeio e investimento ${ }^{19}$. Além disso, foi aprovada a Emenda Constitucional no 9520 em 2016, congelando os gastos com saúde e educação por 20 anos, prevendo reajustes apenas com base na inflação. Nesse período, o então ministro da saúde adotou o discurso de eficiência econômica, defendeu a criação de planos privados populares de saúde, bem como a desregulação do setor de saúde suplementar. Em meio a esse cenário e diante de muitos protestos, foi pactuada na Comissão Intergestores Tripartite (CIT) do SUS, em 2017, uma mudança instituindo uma nova PNAB.

Diante desse cenário, o objetivo deste artigo é analisar a PNAB, comparando as versões editadas em 2011 e 2017, identificando continuidades, descontinuidades e agregações nos seus elementos constituintes, cotejando-os com o contexto e conjuntura nacionais na saúde. 


\section{Metodologia}

O objeto das políticas públicas é o Estado em ação, por meio de programas governamentais. A emergência dessas ações, seus mecanismos de operação e prováveis impactos sobre a ordem política e social são o foco de inúmeros estudos sociais, políticos e econômicos. Compreender as singularidades relativas à evolução, modificação e inovação em uma dada política, em um plano de análise política da política ${ }^{21}$, exige destacar as estratégias de ação estatal e a abrangência das mudanças introduzidas ao longo de certo tempo.

Assim, consideram-se aqui as edições da política como eventos políticos resultados de inter-relação entre atores, interesses, ideias e instituições, sendo que estas últimas se modificam ao longo do tempo e se constituem em diferentes arenas permeadas por atores, referências e percepções que afetam as decisões de cada disputa de projeto político 22 .

Ao partir para a análise de uma política, faz-se necessário

[...] perceber que mesmo as políticas governamentais são desenhadas a partir de conflitos e debates entre grupos e sujeitos, expressando interesses em disputa e um dado modo de construção social. Ou seja, nenhuma política formal é distante de um contexto social. Ela é fruto de embates e conflitos de posições e de percepções de mundo23(19).

Neste estudo, considerou-se que a portaria é a face formal da política. A partir de levantamento documental baseado nas portarias que definem e embasam a PNAB entre os anos de 2011 e 2017, complementado com o posicionamento de atores envolvidos, seguiu-se à eleição de alguns componentes para análise comparativa da PNAB, acompanhando seu comportamento, expresso nas noções de continuidade, descontinuidade e agregação. Em razão de nosso objeto, foram escolhidas como dimensões da análise comparativa das portarias: a) Conceitos-chave e princípios e diretrizes gerais para a AB; b) Aspectos organizativos e funcionais das equipes e unidades de saúde; c) Gestão e Financiamento.

As principais fontes documentais foram as portarias $\mathrm{n}^{0} 2.488$, de 2011, e $\mathrm{n}^{\circ} 2.436$, de $2017^{\mathbf{2 4}, 25}$. Foram consideradas, também, normativas relacionadas diretamente com a PNAB, mas que foram publicadas em portarias específicas, não abordadas em profundidade neste estudo.

A leitura interna da portaria considerou a presença de elementos conceituais, discursivos e dispositivos concretos que condicionam, impedem e/ou induzem o funcionamento local da AB. Em uma leitura externa ao texto formal, buscou-se ampliar a análise, considerando a participação dos atores, a agenda de governo, projetos em disputa, processos decisórios, problemas enfrentados e não enfrentados, compondo o contexto, em parte, descrito na introdução deste artigo. Em outras palavras, empreendeu-se uma leitura que considera o 'dentro texto', o fora texto e suas conexões, sem perder de vista que um ato normativo do tipo 'portaria' dá visibilidade imediata a apenas parte desses elementos.

A utilização de documentos públicos como fontes, neste estudo, dispensou avaliação por comitê de ética. As análises ou interpretações a seguir apresentadas são de responsabilidade dos autores. Estas, por sua vez, são resultado da combinação de análise de políticas com uma análise de conteúdo de base temática. Este estudo não teve apoio financeiro para a sua realização.

\section{Resultados}

Os resultados aqui apresentados estão organizados em três quadros que contemplam, cada um, no seu eixo vertical as dimensões de análise escolhidas e, em seu eixo horizontal, as trajetórias destes elementos encontrados nos textos, quer explicitem continuidades, descontinuidades ou agregações. Seguiram-se, adicionalmente, comentários que realçam, de 
maneira descritiva, os pontos mais significativos na concepção dos autores, além de uma breve caracterização dos atores envolvidos no cenário de mudança da PNAB.

Quadro 1. Síntese comparativa dos princípios, diretrizes e conceitos centrais nas edições das PNAB 2011 e 2017

\begin{tabular}{|c|c|}
\hline $\begin{array}{l}\text { Dimensões de análise/ } \\
\text { Comportamento }\end{array}$ & Princípios, diretrizes e conceitos centrais da Atenção Básica \\
\hline Continuidades & $\begin{array}{l}\text { Os princípios e diretrizes aparecem, em suma, conservados na escrita da PNAB } 2017 \text { (univer- } \\
\text { salidade; equidade; integralidade; regionalização e hierarquização; territorialização; população } \\
\text { adscrita; cuidado centrado na pessoa; resolutividade; longitudinalidade do cuidado; coordena- } \\
\text { ção do cuidado; ordenação da rede; participação da comunidade). } \\
\text { O conceito de AB segue praticamente o mesmo. } \\
\text { Permanece a consideração de AB e atenção primária como termos equivalentes, sendo o } \\
\text { primeiro termo de uso mais frequente no texto da PNAB. }\end{array}$ \\
\hline Descontinuidades & $\begin{array}{l}\text { É retirada a palavra 'democrática' do texto na PNAB } 2017 \text { no que se refere ao formato das } \\
\text { práticas de cuidado e de gestão. } \\
\text { A 'humanização' desaparece dos princípios enunciados na PNAB } 2017 \text { ao contrário da edição } \\
\text { anterior. }\end{array}$ \\
\hline Agregações & $\begin{array}{l}\text { Maior detalhamento e repetição da noção de rede e traduções dos princípios do SUS e das } \\
\text { noções das redes na AB. } \\
\text { A incorporação de conceitos, ferramentas e estratégias de outras publicações já existentes } \\
\text { (técnicas e normativas) ao texto desta nova PNAB. } \\
\text { Agregação dos 'cuidados paliativos' e 'vigilância à saúde' ao conceito de AB - vigilância já } \\
\text { estava na PNAB anterior, mas fora do item específico com definição sobre AB, embora pre- } \\
\text { venção, promoção e proteção (associados à vigilância) estejam nas duas. } \\
\text { Explicita-se a proibição na AB de 'qualquer exclusão baseada em idade, gênero, raça/cor, } \\
\text { etnia, crença, nacionalidade, orientação sexual, identidade de gênero, estado de saúde, condi- } \\
\text { ção socioeconômica, escolaridade, limitação física, intelectual, funcional e outras'. }\end{array}$ \\
\hline
\end{tabular}

Fonte: Elaboração própria, 2018.

Os princípios e diretrizes gerais na PNAB de 2017 não trazem mudanças significativas quando comparados à publicação anterior. Contudo, nota-se que as noções de redes e regiões de saúde se apresentam com maior detalhamento.

A conceituação da $\mathrm{AB}$ praticamente mantém o texto das antigas edições, sendo que nesta incorporam-se os 'cuidados paliativos' e enfatiza-se a 'vigilância em saúde'. Não obstante, tais conceitos já eram anunciados em versões anteriores ou em outras políticas e programas, todavia sem o destaque dado na última publicação. Assim, o que parece haver de novo é a agregação desses dois conceitos como característicos da AB.

Apesar de serem mantidos em equivalência os termos 'atenção básica' e 'atenção primária à saúde' na PNAB de 2017, com a condição de estarem associados aos princípios e diretrizes no documento explicitado, percebe-se maior utilização e frequência do primeiro termo.

Enquanto descontinuidades significativas a esta dimensão de análise, observou-se a retirada das palavras 'democrática' e 'humanização', sendo que uma se referia, na PNAB de 2011, ao formato das práticas de cuidado e de gestão, e a outra era apresentada como um dos princípios, respectivamente.

Na PNAB 2017, estão identificadas o que poderiam ser as causas das 'diferenciações excludentes' indicadas na PNAB de 2011, no acesso e acolhimento do serviço de saúde, ressaltando a proibição dessas (distinções acompanhadas de exclusão devido a condições como idade, gênero, orientação sexual, raça/cor, entre outras). 
Quadro 2. Síntese comparativa dos aspectos organizativos e funcionais nas edições das PNAB 2011 e 2017

\begin{tabular}{|c|c|}
\hline $\begin{array}{l}\text { Dimensões de análise/ } \\
\text { Comportamento }\end{array}$ & Aspectos organizativos e funcionais das equipes e unidades de saúde \\
\hline Continuidades & $\begin{array}{l}\text { Permanece a afirmação discursiva da Estratégia Saúde da Família (ESF) como modalidade } \\
\text { prioritária de implantação da AB no Brasil. } \\
\text { Os tipos de profissionais das Equipes de Saúde da Família (EqSF) e suas atribuições (com } \\
\text { exceção dos ACS), no geral, permanecem. } \\
\text { Os tipos de equipes especiais e para populações específicas (consultório na rua, ribeirinhas } \\
\text { etc.) continuam, embora seja sinalizada a perspectiva de progressiva incorporação nas moda- } \\
\text { lidades mais usuais de equipes. } \\
\text { As possibilidades de composição dos profissionais dos Núcleos de Apoio à Saúde da Família } \\
\text { (Nasf) são mantidas, mas a carga horária não está detalhada. } \\
\text { O denominador para cálculo do número de equipes por município permanece sendo } 2.000 \\
\text { (na PNAB de } 2011 \text {, era } 2.400 \text {, mas a portaria } 2.355 \text { de } 2013 \text { já havia modificado para esse } \\
\text { denominador. } \\
\text { Ambas sugerem considerar elementos como o risco e a vulnerabilidade social como parâme- } \\
\text { tros para definição do número de pessoas/equipe. }\end{array}$ \\
\hline Descontinuidades & $\begin{array}{l}\text { A PNAB } 2017 \text { reconhece outras formas de organização da AB para além da saúde da família. } \\
\text { O número recomendado de pessoas por EqSF passa a ser a faixa de } 2.000 \text { - } 3.500 \text { pessoas, } \\
\text { sem a recomendação de } 3.000 \text { pessoas/equipe (como média recomendada) da PNAB ante- } \\
\text { rior. A PNAB } 2011 \text { indicava apenas o limite máximo de } 4.000 \text { /equipe, sem mínimo. } \\
\text { O número mínimo de ACS/equipe, que era de } 4 \text { na PNAB anterior, não está definido na atual, } \\
\text { passando, portanto, a ser de } 1 \text { ACS/equipe. } \\
\text { Passa a haver recomendação de que os ACS devem cobrir 100\% da população em condições } \\
\text { de maior risco e vulnerabilidade (sem parâmetros objetivos usados nesta definição), e não } \\
\text { mais } 100 \% \text { da população da EqSF. } \\
\text { Foi retirada da PNAB de } 2017 \text { a previsão de que parte da carga horária dos profissionais ( } 8 \\
\text { horas semanais) pudesse ser destinada para atividades de formação. } \\
\text { Foi retirada a possibilidade de EqSF terem médicos com carga horária de } 20 \text { horas e } 30 \text { horas, } \\
\text { ficando apenas } 40 \text { horas para todos os profissionais. } \\
\text { As Equipes de Saúde Bucal passam também a poder cobrir as unidades básicas tradicionais. } \\
\text { Os Nasf passam a se chamar Núcleo Ampliado de Saúde da Família e Atenção Básica (Nasf- } \\
\text {-AB), suprimindo a noção de 'apoio'. } \\
\text { Ainda que a PNAB } 2017 \text { traga a educação permanente como importante para o processo de } \\
\text { trabalho da atenção básica, é dada menor ênfase. } \\
\text { O Programa Saúde na Escola (PSE) na PNAB } 2017 \text { está apenas como um dos itens que devem } \\
\text { ter financiamento federal, sem especificações. }\end{array}$ \\
\hline Agregações & $\begin{array}{l}\text { A PNAB } 2017 \text { traz como responsabilidade tripartite a garantia do transporte em saúde para } \\
\text { equipes e usuários. } \\
\text { A introdução dos conceitos de 'padrão essencial' e 'padrão ampliado' na conformação e clas- } \\
\text { sificação das ações e serviços, sem detalhamento. } \\
\text { A PNAB } 2017 \text { possibilita a incorporação do ACE como parte da EqSF. } \\
\text { As Equipes de Atenção Básica (EqAB) estão previstas com cargas horárias mínimas de } 10 \\
\text { horas dos seus profissionais, sem obrigatoriedade de ACS na sua composição, com indicação } \\
\text { de novo financiamento de custeio. } \\
\text { Integração entre vigilância e atenção básica com recomendação de unificação das ações dos } \\
\text { agentes comunitários de saúde e dos agentes de combate às endemias. } \\
\text { Novas competências dos ACS, por meio de formação específica, assistidos por profissional de } \\
\text { nível superior. } \\
\text { Os Nasf-AB passam a cobrir também as chamadas unidades básicas tradicionais. } \\
\text { Recomendação de que as UBS tenham } 4 \text { equipes para atingirem o seu potencial resolutivo } \\
\text { (PNAB anterior recomendava o máximo de } 12.000 \text { pessoas por UBS com ESF em áreas urba- } \\
\text { nas, e de } 18.000 \text { pessoas para UBS tradicionais). } \\
\text { Profissionais da ESF só podem atuar em uma equipe. }\end{array}$ \\
\hline
\end{tabular}

Fonte: Elaboração própria, 2018. 
Nos aspectos organizativos e funcionais, encontram-se as descontinuidades e agregações mais substantivas na PNAB 2017. Ressalta-se que tais aspectos dizem da possibilidade de modificação concreta da realização da AB no País. A flexibilidade trazida pela nova PNAB se expressa em muitos momentos do documento, certas vezes de maneira nebulosa em um discurso de adequação às necessidades locorregionais.

As descontinuidades podem ser percebidas quando se lê a possibilidade de redução do número de ACS por EqSF (no mínimo um), de maneira a vincular esse quantitativo aos territórios ditos de maior risco e mais vulneráveis, ao mesmo tempo que se oportuniza a possibilidade de aumento de suas atribuições; inclusive com recomendação de unificar suas ações com as dos ACE (e de incorporação desse último como parte da EqSF) e, ainda, facultar competências atualmente desempenhadas pelos técnicos de enfermagem (como: aferição de pressão, glicemia capilar, aferição de temperatura axilar e curativos limpos).

Ainda que as atribuições das outras categorias profissionais de saúde que compõem as EqSF tenham permanecido praticamente idênticas à PNAB de 2011, houve alteração quanto à exigência da carga horária, pois agora todos os médicos devem cumprir 40 horas semanais. As equipes de $\mathrm{AB}$ (no formato tradicional), porém, estão previstas com profissionais contratados para cumprir carga horária semanal mínima de 10 horas, sem obrigatoriedade do ACS e custeadas por novo financiamento (até então o único recurso do tipo PAB variável baseado neste tipo de equipe era o do PMAQ, desde que houvesse equipe tradicional certificada por este programa).

A recomendação de pessoas por EqSF também é modificada. Enquanto a PNAB 2011 fazia menção apenas ao limite máximo de 4.000 pessoas/equipe e 3.000/equipe como média recomendada, a PNAB 2017 coloca que cada EqSF deve ser responsável por 2.000-3.5000 pessoas. Ressalta-se, porém, que as duas publicações continuam sugerindo que esse número esteja alinhado às questões de vulnerabilidade do território.

Os Nasf, quando de sua criação, em 2008, tinham por objetivo ampliar a capacidade de cuidado na $\mathrm{AB}$, calcados na lógica do apoio matricial. A PNAB 2017 não traz mudanças quanto às categorias profissionais do Nasf nem sobre sua carga horária, contudo, a nova nomenclatura parece anunciar outra concepção do trabalho. Renomeados como Núcleos Ampliados de Saúde da Família e Atenção Básica (Nasf-AB), podem perder a função de apoio e, pela possibilidade de cobrir também as unidades básicas tradicionais, podem ter uma interferência negativa no seu formato de funcionamento (que já é um desafio mesmo nas EqSF), pela maior dificuldade de operar na lógica do apoio matricial com este tipo de UBS (considerando o regime de cargas horárias previsto bem como a baixa indução para funcionarem com atributos e diretrizes observados na ESF).

Ao entender o SUS como espaço de formação, a PNAB 2011 previa que até 8 horas semanais dos profissionais das EqSF pudessem ser utilizadas para atividades de formação, educação permanente, apoio matricial e plantão na rede de urgência, o que não mais se encontra na publicação de 2017. Percebese também, enquanto descontinuidade, uma menor valorização da educação permanente, peça-chave para o processo de trabalho na AB. O Programa Saúde na Escola, na PNAB 2017, aparece timidamente como um dos itens que devem ter financiamento federal, carente de especificações.

Percebe-se, na PNAB mais recente, uma diferenciação das ações e serviços da $\mathrm{AB}$ que passam a ser classificadas a partir dos conceitos de 'padrão essencial' (ações e procedimentos básicos de acesso e qualidade) e 'padrão ampliado' (estratégicos para atingir altos padrões de acesso e qualidade), mesmo com escassez de detalhes. Sobre isso, há que se mencionar o risco de se abrir para uma atenção simplificada e seletiva. 
Quadro 3. Síntese comparativa dos aspectos de gestão e financiamento nas edições das PNAB 2011 e 2017

\begin{tabular}{|c|c|}
\hline $\begin{array}{l}\text { Dimensões de análise/ } \\
\text { Comportamento }\end{array}$ & Aspectos de gestão e financiamento da Atenção Básica \\
\hline Continuidades & Grande maioria das responsabilidades dos três entes federados permanecem. \\
\hline \multicolumn{2}{|l|}{ Descontinuidades } \\
\hline Agregações & $\begin{array}{l}\text { A figura do gerente de Unidade Básica de Saúde (UBS) e suas atribuições. } \\
\text { Constante menção, no texto da nova PNAB, sobre as realidades de cada local e possibilidades } \\
\text { de adaptação (por vezes isso ficando confuso e até contraditório, quando acompanhando de } \\
\text { uma definição normativa fechada) dos parâmetros propostos, de forma a ampliar o poder do } \\
\text { gestor municipal. } \\
\text { A previsão (não detalhada) de agregação de modalidade de financiamento federal com recur- } \\
\text { sos condicionados à abrangência da oferta de ações e serviços. } \\
\text { Indicação de financiamento 'regular e automático' pelas secretarias estaduais de saúde para } \\
\text { os municípios, embora a PNAB não tenha nenhum dispositivo concreto para isso. } \\
\text { Validade de } 4 \text { meses para o credenciamento de novas equipes pelo Ministério da Saúde (pra- } \\
\text { zo para serem implantadas no município após o credenciamento-autorização solicitado). }\end{array}$ \\
\hline
\end{tabular}

Fonte: Elaboração própria, 2018

Em se tratando da gestão, percebeu-se a manutenção majoritária das condições da PNAB anterior. Dentre as agregações, pode-se citar a menção da figura do gerente de serviço, objetivando qualificar o processo de trabalho nas UBS, com recomendações de atribuições para esse profissional - que deve ser qualificado, com nível superior, não membro de EqSF e com experiência na AB. Considera-se positiva a introdução de uma gerência desde que envolva critérios profissionais e não meramente político-eleitorais. Outra agregação que remete à gestão é a constante menção sobre a necessidade de adequação do desenho da $\mathrm{AB}$ às diferentes realidades de cada local e possibilidades de adaptação por meio do gestor municipal, com autonomia nas suas escolhas. No entanto, isso muitas vezes não está claro, permite uma confusão e algumas vezes denota contradição quando acompanhado de uma definição normativa fechada.

Em se tratando do financiamento, destacamos como elemento de continuidade que a maioria das responsabilidades das esferas federal, estadual e municipal são mantidas, em que pese a menção ao repasse mensal e regular a ser feito pelos estados aos municípios (importante, porém de baixa efetividade considerando a autonomia dos estados). A agregação trazida pela PNAB 2017, neste item, é a previsão, sem detalhes, de modalidade de financiamento federal com recursos condicionados à abrangência da oferta de ações e serviços.

Após as mudanças trazidas pela PNAB 2017, foi estabelecido, em 2018, apenas o financiamento específico para as equipes de $\mathrm{AB}$ tradicional e para gerente de UBS. Até o momento, não houve qualquer reajuste dos valores per capita do PAB Fixo (apenas atualização da população), tampouco dos diferentes componentes do PAB Variável mais relacionado com a ESF (Nasf, EqSF, ACS, Saúde Bucal, PMAQ).

No que se refere ao cenário, vários atores (além dos gestores municipais, estaduais e federal) se posicionaram contrariamente à revisão da PNAB, incluindo o Centro Brasileiro de Estudos de Saúde (Cebes) e a Associação Brasileira de Saúde Coletiva (Abrasco) 26. O Conselho Nacional de Saúde (CNS) emitiu recomendação contrária à revisão neste tempo e indicando necessidade de maior discussão. Tendo protagonismo central do Conselho Nacional de Secretarias Municipais de Saúde (Conasems) e do Ministério da Saúde (MS), e apoio do 
Conselho Nacional de Secretarias Estaduais de Saúde (Conass) ${ }^{27}$, deu-se uma mudança normativa a despeito de contestações por diversas entidades e movimentos da sociedade civil, colocando em xeque a legitimidade do processo ${ }^{28}$.

\section{Discussão}

Com base nos resultados apresentados, cabe destacar que, em documentos do tipo portaria, costumam figurar conteúdos de teor conceitual, normativo, procedimental e recomendações, e que tais conteúdos não são equivalentes, carregando diferentes sentidos e possibilidades de apropriação por atores concretos, e de influência sobre realidades.

A despeito de haver agregações positivas na atual PNAB, tais elementos aparecem, sobretudo, no plano conceitual e discursivo (ou como recomendação), sem dispositivos concretos que busquem a sua efetivação de modo não apenas novo como também mais efetivo.

Contudo, outras 'novidades' parecem problemáticas, tais como o modo colocado de integração entre vigilância em saúde e $A B$ (ignorando suas especificidades), bem como as noções de padrão essencial e ampliado, que podem ter algum sentido em termos de desempenho (no quadro do PMAQ), mas na portaria são apresentados de modo genérico e com risco de apropriações que retornam à APS seletiva.

Ainda que as palavras importem (inclusive por expressarem consensos, disputas e narrativas das 'forças' envolvidas na formulação e decisão da política), ao considerá-las em uma portaria, é fundamental atentar para os efeitos concretos que elas podem ou não produzir, observando os dispositivos com potencial de interferir nas realidades, bem como sua direcionalidade. Nesse sentido, destaca-se, na PNAB, a mudança nas modalidades e composição das equipes. Trata-se da definição de que as EqSF devem ter, agora, no mínimo um (não mais quatro)
ACS, bem como da previsão de novos incentivos financeiros para modalidades de $\mathrm{AB}$ não necessariamente baseadas em atributos e diretrizes da APS, tal qual adotadas na ESF. A força desses dispositivos provém do seu caráter indutor (ou permissivo) e da receptividade dos atores aos quais se dirige. Na prática, isso significa que, se os gestores municipais do SUS (que em última instância respondem pela contratação de profissionais e pela organização da $\mathrm{AB}$ nos municípios) visualizarem nisso uma possibilidade de enfrentar/minimizar o subfinanciamento ou de os serviços se adequarem mais à realidade (segundo suas perspectivas), isso passa a ter mais chances de acontecer do que havia até a edição da atual PNAB.

No entanto, a normativa atual ainda não obriga a mudança, sendo ainda possível, por exemplo, manter cinco ACS na EqSF, se isso for uma decisão por convicção do gestor ou decorrente de negociações e pressões envolvendo atores locais. Contudo, isso parece menos provável de acontecer no cenário atual. A existência de novo financiamento para outro tipo formato de $\mathrm{AB}$, entretanto, pode induzi-lo, a depender dos valores de repasse e da situação local, gerando não só diminuição de ACS como também estagnação ou mesmo diminuição da cobertura da ESF. Cabe indicar que o dimensionamento da $A B$ tradicional atualmente existente é de difícil realização (tendendo a ser pouco preciso), e que as unidades básicas tradicionais, diferentemente da imensa maioria das EqSF, tiveram uma presença inexpressiva nos ciclos do PMAQ, indicando pouca abertura para mudança de sua lógica instituída (com fracos graus de territorialização, adscrição, vínculo, continuidade e trabalho em equipe).

Ainda no que se refere às modalidades de organização da $\mathrm{AB}$, entende-se que os elementos de maior centralidade na orientação para uma APS abrangente e integral são os atributos e diretrizes, não apenas os formatos, mas há diferentes chances de sucesso da APS segundo a composição e processo de 
trabalho das suas equipes. Nesse sentido, tal como ocorreu na PNAB de 2011, que previu a criação de equipes fluviais e consultórios na rua organizados e com funcionamento diverso das equipes de saúde da família habituais, a diversidade de formatos de APS não é algo negativo a priori, sobretudo quando elas visam responder às necessidades de territórios e grupos populacionais específicos. Entretanto, a última mudança da PNAB não foi acompanhada por uma discussão ampla e consistente nesse sentido, além de se colocar em uma conjuntura econômica e política muito arriscada. Equipes com profissionais de 10 horas, por exemplo, como na composição trazida pela PNAB 2017, são estruturalmente muito diferentes de equipes com profissionais de 30 ou 40 horas e necessariamente multiprofissionais. Ainda que a carga horária não seja determinante último da lógica e dos efeitos do trabalho, tendem a produzir e a condicionar responsabilizações e pertencimentos distintos. Da mesma forma, trabalhar em comunidades com marcante vulnerabilidade social tendo na equipe figuras como os ACS pode ser muito diferente de fazê-lo sem tal ator ou com presença escassa deste.

Destaca-se ainda o tema dos ACS, pois, de um lado, observa-se a relevância política dessa categoria (evidenciada pela aprovação de suas leis no congresso nacional e também por usos eleitorais dos ACS nos espaços municipais) e, de outro lado, alterações no trabalho dos ACS decorrentes da mudança do seu perfil de escolaridade e formação, da progressiva transformação em profissão, das mudanças no escopo de ações e ofertas das EqSF e do perfil demográfico e epidemiológico da população geral. Esses elementos indicam fortemente a necessidade de aprofundar o debate sobre o ACS nos tempos atuais, em um movimento orientado pelas necessidades dos usuários, pelo fortalecimento da APS e pelo desenvolvimento profissional do ACS, não isento de tensões e de riscos. Por sua vez, a diminuição do número mínimo de ACS por ESF e as iniciativas nacionais de formação em técnicos de enfermagem para os ACS, se concretizadas, tendem a modificar fortemente o perfil e as competências dos ACS nos próximos anos, com impactos sobre os modos de organização da ESF ${ }^{29,30}$.

No processo de revisão da PNAB de 2017, os gestores municipais tiveram um protagonismo destacado, acompanhando uma tendência observada em outras pautas do mesmo período, tais como a revisão dos blocos de financiamento. É sabido que os municípios tiveram papel central na agenda de descentralização da saúde nos anos 1990 (sobretudo com a municipalização), sendo a ESF um revelador desse processo ${ }^{31}$. Ao mesmo tempo que o pleito por mais financiamento da saúde esteve na pauta dos gestores municipais ao longo das décadas de implantação do SUS, os municípios foram se tornando um dos grandes responsáveis pela sustentação financeira do SUS, ainda que a participação federal continue sendo insuficiente, porém muito relevante ${ }^{31}$. Esse processo, aliado à cultura vertical e fragmentada do MS, à diversidade do País e à atuação dos órgãos de controle e de justiça, parece explicar, em parte, o discurso por mais autonomia bastante presente na agenda do Conasems. Entretanto, a reivindicação histórica e legítima dos gestores municipais por mais autonomia talvez deva ser reinterpretada no contexto atual, à luz do cenário de agravamento do subfinanciamento, colocando em exame a direção que a ampliação da autonomia pode seguir, bem como o comportamento das diferentes forças locais diante das flexibilizações aportadas. Assim, questiona-se o quanto áreas ainda pouco legitimadas socialmente, como a $\mathrm{AB}$ e a vigilância em saúde, quando comparadas com o imaginário do consumo de ações e serviços médicos de urgência e especializados, tornar-se-ão mais vulneráveis a partir dessas medidas.

Na agenda de revisão da PNAB, houve uma clara divisão, colocando, grosso modo, de um lado, o mundo dos gestores formais e, de outro, parte significativa dos atores não 
governamentais que fazem controle e participação social no SUS. Nessa disputa, venceram os gestores, contribuindo para ampliar a cisão entre segmentos historicamente relevantes na construção do SUS ${ }^{32}$.

Por fim, um dos elementos importantes a estudar em uma política são os problemas reconhecidos e enfrentados por ela. No caso em questão, poderiam ser um conjunto de desafios e nós críticos da $\mathrm{AB}$, tais como a insuficiente legitimidade social, o baixo grau de coordenação de cuidado e integração com os demais serviços das redes de atenção, a necessidade de melhorar o acesso e os modos de cuidar nas unidades de saúde, a necessidade de formar, prover e fixar bons profissionais na APS, a superação do subfinanciamento, entre outros. Os dispositivos mais efetivos da PNAB de 2017 e seus desdobramentos e iniciativas colaterais não dialogam consistentemente com tais desafios. Apenas a título indicativo, o eixo 'formação' do PMM, aprovado em lei (com reorientação da graduação e da residência médicas), estratégico para a $\mathrm{AB}$, não está na agenda dos gestores do SUS. Nem mesmo a luta por mais financiamento para o SUS parece ser mais uma agenda tripartite central. Se políticas buscam atender a 'urgências', é importante indagar e colocar em análise a que urgências a PNAB de 2017 buscou responder, bem como acompanhar sua trajetória, apropriações e efeitos.

\section{Considerações finais}

A recente mudança da PNAB, em 2017, diferentemente de 2011, deu-se em uma conjuntura de crise política e econômica do País, que vem incidindo de forma avassaladora sobre políticas sociais. Se forem efetivamente considerados os dispositivos da PNAB que induzem, impedem ou condicionam mudanças, pode-se dizer que os propósitos centrais dessa política são a diminuição dos ACS e a mudança de seu perfil, bem como a priorização da chamada $\mathrm{AB}$ tradicional em detrimento da ESF, com maior autonomia e flexibilidade para a gestão municipal. Se tentarmos configurar uma 'trama', relacionando os elementos da PNAB entre si e com a conjuntura (do SUS e do país), veremos que o seu principal efeito tende a ser o desmonte da ESF (ao invés do enfrentamento dos seus problemas, limites e desafios), em uma conjuntura em que seria desejável manter o que fora conquistado até o momento. A concentração de poder nos gestores formais do SUS nesse processo evidencia também que a gestão governamental tripartite do SUS não tem tido seu poder de fogo contrabalanceado pela sociedade civil e pelos trabalhadores, produzindo mais uma cisão nas bases de sustentação do SUS, em um cenário em que esta grande política pública tem sua existência gravemente ameaçada.

\section{Colaboradores}

Melo EA, Mendonça MHM, Oliveira JR e Andrade CGL contribuíram substancialmente para a concepção, planejamento, análise, elaboração do rascunho, revisão crítica do conteúdo e aprovação da versão final do manuscrito. 


\section{Referências}

1. Kuschnir R, Chorny AH. Redes de atenção à saúde: contextualizando o debate. Ciênc Saúde Colet. 2010 maio; 15(5):2307-2316.

2. Merhy EE, Franco TB. PSF: contradições de um programa destinado à mudança do modelo tecnoassistencial. In: Merhy EE, Magalhães Júnior HM, Rimoli J, et al., organizadores. O trabalho em saúde: Olhando e experienciando o SUS no cotidiano. São Paulo: Hucitec; 2003. p. 55-124.

3. Organização Mundial de Saúde. Fundo das Nações Unidas pela Infância. Relatório da Conferência Internacional sobre Cuidados Primários de Saúde Alma-Ata, URSS, 6-12 de setembro de 1978 [internet]. Brasília, DF: Unicef; 1979 [acesso em 2018 maio 25]. Disponível em: http://apps.who.int/iris/bitstream/ handle/10665/39228/9241800011_por.pdf?sequenc $\mathrm{e}=5$ \&isAllowed=y\&ua $=1$.

4. Starfield B. Atenção primária: equilíbrio entre necessidades de saúde, serviços e tecnologia. Brasília, DF: Ministério da Saúde; 2002.

5. Organização Pan-Americana da Saúde. Renovação da atenção primária em saúde nas Américas: documento de posicionamento da Organização Pan-Americana da Saúde/Organização Mundial da Saúde (OPAS/OMS). Washington, DC: OPAS; 2008.

6. Viana ALD, Dal Poz MR. A reforma do sistema de saúde no Brasil e o programa de saúde da família. Physis. 2005; 15(sup):225-264.

7. Giovanella L, Mendonça MHM. Atenção primária à saúde. In: Giovanella L, Escorel S, Lobato LVC, et al., organizadores. Políticas e sistema de saúde no Brasil. Rio de Janeiro: Fiocruz; Cebes; 2012. p. 493545.

8. Escorel S, Giovanella L, Mendonça MHM, et al. Avaliação da implementação do programa saúde da família em dez grandes centros urbanos: síntese dos principais resultados. 2. ed. Brasília, DF: Ministério da Saúde; 2005.
9. Brasil. Ministério da Saúde. Secretaria de Atenção à Saúde. Departamento de Atenção Básica. Cobertura da atenção básica. 2017 [acesso em 2018 maio 20]. Disponível em: http://dab.saude.gov.br/portaldab/.

10. Macinko J, Oliveira VB, Turci MA, et al. The influence of primary care and hospital supply on ambulatory care-sensitive hospitalizations among adults in Brazil, 1999-2007. Am. J. Public Health. 2011 out; 101(10):1963-1970.

11. Giugliani C, Harzheim E, Duncan MS, et al. Effectiveness of community health workers in Brazil: a systematic review. J. Ambul. Care Manage. 2011; 34(4):326-338.

12. Brasil. Ministério da Saúde. Portaria $n^{\circ} 4.279$, de 30 de dezembro de 2010. Estabelece diretrizes para organização da rede de atenção à saúde no âmbito do Sistema Único de Saúde (SUS), 2010. Diário Oficial da União. 30 Dez 2010.

13. Brasil. Ministério da Saúde. Portaria $n^{\circ} .648$, de 28 de março de 2006. Política nacional de atenção básica. Diário Oficial da União. 26 Mar 2006.

14. Pinto H, Sousa ANA, Ferla AA. O programa nacional de melhoria do acesso e da qualidade da atenção básica: várias faces de uma política inovadora. Divulg. saúde debate. 2014 out; 51:43-57.

15. Pinto HA, Koerner RS, Silva DCA. Prioridade se traduz em mais e melhores recursos para a atenção básica [internet]. Brasília, DF: Abrasco; 2012 [acesso em 2018 maio 4]. Disponível em: http:// www.rededepesquisaaps.org.br/wpcontent/uploads/2012/06/artigoprioridade.pdf.

16. Campos GWS, Pereira Júnior N. A atenção primária e o programa mais médicos do sistema único de saúde: conquistas e limites. Ciênc Saúde Colet. 2016; 21(9):2655-2663.

17. Mendes A, Marques RM. O financiamento da atenção básica e da estratégia saúde da família no sis- 
tema único de saúde. Saúde debate. 2014 out-dez; 38(103):900-916.

18. Brasil. Lei $\mathrm{n}^{0} 12.994$, de 17 de junho de 2014. Altera a Lei $n^{\circ} 11.350$, de 5 de outubro de 2006, para instituir piso salarial profissional nacional e diretrizes para o plano de carreira dos agentes comunitários de saúde e dos agentes de combate às endemias. Diário Oficial da União. 18 Jun 2014.

19. Brasil. Ministério da Saúde. Portaria no 3.392, de 28 de dezembro de 2017. Altera a Portaria de Consolidação n. 6/GM/MS, de 28 set. 2017, para dispor sobre o financiamento e a transferência dos recursos federais para as ações e os serviços públicos de saúde do Sistema Único de Saúde. Diário Oficial da União. 14 dez 2017.

20. Brasil. Presidência da República. Casa Civil. Emenda Constitucional $\mathrm{n}^{\circ}$ 95, de 15 de dezembro de 2016. Altera o ato das disposições constitucionais transitórias, para instituir o novo regime fiscal, e dá outras providências. Diário Oficial da União. 15 Dez 2016.

21. Lenhardt G, Offe C. Teoria do Estado e política social. In: Offe C. Problemas estruturais do Estado capitalista. Rio de Janeiro: Tempo Brasileiro; 1984. p. 10-53.

22. Menicucci TMG. Prefácio. In: Machado CV, Baptista TW, Lima LD. Políticas de saúde no Brasil: continuidades e mudanças. Rio de Janeiro: Fiocruz; 2012.

23. Mattos RA, Baptista TWF, organizadores. Caminhos para análise das políticas de saúde. Porto Alegre: Rede Unida, 2015.

24. Brasil. Ministério da Saúde. Política nacional de atenção básica. Brasília, DF: Ministério da Saúde; 2012.

25. Brasil. Ministério da Saúde. Portaria no 2.436, de 21 de setembro de 2017. Aprova a política nacional de atenção básica, estabelecendo a revisão de diretrizes para a organização da atenção básica, no âmbito do sistema único de saúde (SUS). Diário Oficial da União. 22 Set 2017.
26. Reis V. Contra a reformulação da PNAB - nota sobre a revisão da política nacional de atenção básica [internet]. Rio de Janeiro: Abrasco; 2017 [acesso em 2018 maio 12]. Disponível em: https://www.abrasco. org.br/site/outras-noticias/notas-oficiais-abrasco/ contra-reformulacao-da-pnab-nota-sobre-revisao-da-politica-nacional-de-atencao-basica/29798/.

27. Conselho Nacional de Secretários de Saúde; Conselho Nacional de Secretarias Municipais de Saúde. Nota conjunta Conasems e Conass sobre a reformulação PNAB [internet] Brasília, DF: Conass; Conasems; 2017 [acesso em 2018 maio 17]. Disponível em: http://www.conass.org.br/nota-conjunta-conasems-e-conass-sobre-reformulacao-pnab/.

28. Brasil. Ministério da Saúde. Conselho Nacional de Saúde. Recomendação $\mathrm{n}^{0} 035$ de 11 de agosto de 2017. Sobre a revisão da política nacional de atenção básica (PNAB). Reunião no 296. Brasília, DF: 2017. Disponível em: http://conselho.saude.gov.br/recomendacoes/2017/Reco035.pdf.

29. Brasil. Ministério da Saúde. Portaria no 83 de 10 de janeiro de 2018. Institui o programa de formação técnica para agentes de saúde - Profags. Diário Oficial da União. 12 Jan 2018.

30. Morosini MV, Fonseca A. Revisão da política nacional de atenção básica numa hora dessas? Cad Saúde Pública. 2017 dez; 33(1):e00206316.

31. Castro AL, Lima LD, Machado CV. Financiamento da atenção básica no SUS. Rede de Pesquisa em APS/Abrasco. In: Seminário Preparatório ao $12^{\circ}$ Congresso Brasileiro de Saúde Coletiva; 2018 mar 20. Rio de Janeiro: Ensp/Fiocruz; 2018.

32. Campos GWS. Reforma política e sanitária: a sustentabilidade do SUS em questão? Ciênc Saúde Colet. 2007 mar-abr; 12(2):301-306.

\footnotetext{
Recebido em: 29/05/2018

Aprovado em: 23/08/2018

Conflito de interesses: inexistente

Suporte financeiro: não houve
} 